\title{
Optimization of dynamic maceration of Clausena anisata (Willd.) Hook. f. ex Benth. leaves to maximize trans-anethole content
}

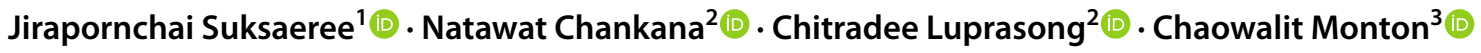

Received: 10 October 2020 / Accepted: 17 March 2021 / Published online: 31 March 2021

(C) The Author(s) 2021 OPEN

\begin{abstract}
Trans-anethole possesses several biological and pharmacological effects. It is also used as masking agent in household products and as a flavoring agent in food. Clausena anisata (Willd.) Hook. f. ex Benth. leaves are reported as a source of trans-anethole that makes their anise-like odor. This work sought to optimize the dynamic maceration of $C$. anisata leaves to maximize the trans-anethole content. The circumscribed central composite experimental design was applied to investigate the effects of extraction temperature and time on extraction yield, trans-anethole content in the extract, and trans-anethole content in the plant raw material. The results showed that the extraction yield was high when C. anisata leaves were extracted over a long extraction time, while the extraction temperature had a lesser effect on the extraction yield. Trans-anethole content in the extract and plant raw material determined using a linear, specific, precise, and accurate HPLC method was high when a medium extraction temperature with a short extraction time was used. The optimal condition that maximized trans-anethole content involved an extraction temperature of $61.8^{\circ} \mathrm{C}$ and an extraction time of $12.9 \mathrm{~min}$, respectively. The percentage error of the prediction conducted by computer software was low, suggesting that the prediction was highly accurate. In conclusion, the optimal condition of dynamic maceration obtained from this work could be used as a guide for maximizing trans-anethole content from C. anisata leaves.
\end{abstract}

Keywords Trans-anethole · Clausena anisata · Dynamic maceration · Optimization

\section{Introduction}

Clausena anisata (Willd.) Hook. f. ex Benth. is a herbal medicinal plant belonging to the Rutaceae or Citrus family. It has been investigated for several activities including analgesic [1], antidiabetic [2, 3], anti-inflammatory $[4,5]$, antimalarial [1], antimicrobial [3, 6-9], antioxidant $[3,10,11]$, antipyretic [4], cytotoxic [6], larvicidal [12-16], smoking cessation aid [17], and wound healing [11] effects. The five major compounds containing in essential oils of $C$. anisata leaves growing in NorthCentral Nigeria are anethole $(31.3 \%)$, trans- $\beta$-ocimene $(20.0 \%)$, caryophyllene $(10.5 \%)$, estragole $(6.9 \%)$, and a-pinene (6.7\%) [18]. Pavela et al. [14] revealed that the essential oils of $C$. anisata leaves from Cameroon include trans-anethole (64.6\%), trans-methyl isoeugenol (16.1\%), p-cymene (2.9\%), $\gamma$-terpinene (2.4\%), and germacrene $\mathrm{D}$ (2.2\%). High amounts of methyl chavicol and trans-anethole were previously reported. In their study, Ekundayo et al. [19] noted that the essential oil composition of $C$. anisata leaves from Nigeria contains $92.7 \%$ methyl chavicol. The essential oil compositions of $C$. anisata leaves from Ghana, Togo, and Benin have also been shared: three samples of $C$. anisata leaf essential oil contained methyl chavicol concentrations of $85.4-99.7 \%$, while another three samples contained concentrations ranging

Chaowalit Monton, chaowalit@rsu.ac.th | 'Department of Pharmaceutical Chemistry, College of Pharmacy, Rangsit University, Pathum Thani 12000, Thailand. ' 2 un Herb Thai Chinese Manufacturing, College of Pharmacy, Rangsit University, Pathum Thani 12000 , Thailand. ${ }^{3}$ Drug and Herbal Product Research and Development Center, College of Pharmacy, Rangsit University, Pathum Thani 12000 , Thailand. 
from 95.5 to $98.9 \%$ [20]. Elsewhere, different essential oil compositions were observed; for example, in comparison with the above, Govindarajan [16] reported the five major compounds in essential oils of $C$. anisata leaves from India are $\beta$-pinene $(32.8 \%)$, sabinene $(28.3 \%)$, germacrene $D(12.7 \%)$, estragole (6.4\%), and linalool (5.9\%).

Clausena anisata leaves generate an anise-like odor, which is the smell of a major essential oil: trans-anethole. Trans-anethole is a clear, colorless to amber-colored liquid with an anise-like flavor. It is slightly soluble in water but highly soluble in ethanol. It is 13 times sweeter than sugar and used in many alcoholic drinks. Further, it is also used as a masking agent in household products and as a flavoring agent in food. According to its pharmacological effects, it possesses several properties such as antioxidant, antimicrobial, anthelmintic, insecticidal, expectorant, spasmolytic, antinociceptive, anti-inflammatory, gastroprotective, and sedative activities [21].

The extraction procedure is an essential step of plant composition analysis and the study of the activity of the essential oils. A suitable extraction condition provides the desired plant bioactive constituents with a small degree of degradation [22]. As such, the selection of an extraction condition is an important parameter. Design of Experiment (DOE) is a tool that is used to systemically examine different types of problems occurring within research, development, or production step [23]. DOE is a multipurpose tool that can be used in many circumstances, i.e., design for comparisons, screening of variables, transfer function identification, optimization, and robust design [24]. It is the most popular tool in various scientific areas, such as medicine, engineering, biochemistry, genetics, physics, astronomy, and computer sciences. [24]. The modern experimental design exhibited superior advantages compared with the traditional One Factor at a Time (OFAT) trialing such as less time and financial consuming, less pharmaceutical substance use, interaction effect can be identified, and surface response can be characterized [25]. Application of DOE in the extraction process of herbal plant is an interesting methodology. To the best of our knowledge, there is no work reported about the optimization of extraction of trans-anethole from $C$. anisata leaves. The objective of this work was to optimize the dynamic maceration of $C$. anisata leaves to maximize the trans-anethole extracted. The circumscribed central composite experimental design was applied to investigate the effects of two factors-extraction temperature and extraction time-on the three responses of extraction yield, trans-anethole content in the extract, and trans-anethole content in the plant raw material. The authors expect that the optimal condition obtained from this work could be used as a guide for maximizing trans-anethole from C. anisata leaves to use as ingredient of food, beverage, or herbal products.

\section{Materials and methods}

\subsection{Materials}

Trans-anethole (purity 99.6\%) was purchased from SigmaAldrich (St. Louis, MO, USA). Absolute ethanol (AR grade) and methanol (HPLC grade) were purchased from Duksan Pure Chemicals (Kyunggi, Korea). C. anisata leaves were collected in November 2018 from Sing Buri Province, Thailand. The plant sample was identified by Chair Prof. Dr. Nijsiri Ruangrungsi to ensure the right plant species. The voucher specimen was coded as CM-CA003-1-11-2018 was then deposited at the Drug and Herbal Product Research and Development Center, College of Pharmacy, Rangsit University.

\subsection{Optimization of dynamic maceration}

A circumscribed central composite experimental design was applied in this work. The effects of the two factors [i.e., extraction temperature $\left(X_{1}\right)$ and extraction time $\left(X_{2}\right)$ ] on the three responses [i.e., extraction yield $\left(Y_{1}\right)$, transanethole content in extract $\left(Y_{2}\right)$, and trans-anethole content in the plant raw material $\left.\left(Y_{3}\right)\right]$ were investigated. Eight non-center points (Conditions 1-8) with four center points (Conditions 9-12) were selected. Extraction temperature and extraction time were varied for five levels from 40 to $80^{\circ} \mathrm{C}$ and 10 to $30 \mathrm{~min}$, respectively. The coded and actual values of the 12 model conditions obtained from the experimental design are shown in Table 1.

Collected dried leaves of $C$. anisata were pulverized and passed through 20-mesh sieve. Plant powders with particle size of approximately $850 \mu \mathrm{m}$ were obtained. Then, $10 \mathrm{~g}$ of $C$. anisata leaf powder was mixed with $100 \mathrm{~mL}$ of absolute ethanol in a 250-mL Erlenmeyer flask. The mixture was dynamically macerated in a water bath (WNB 14; Memmert GmbH + Co. KG, Büchenbach, Germany) equipped with a shaking device (SV 1422; Memmert GmbH + Co. KG, Büchenbach, Germany) according to the condition shown in Table 1. The shaking device was programmed with an agitation rate of 160 strokes $/ \mathrm{min}$. Then, the slurry was filtered to collect the filtrate. The macerated leaf mixture was extracted again with the same procedure. The extraction was performed three times, the three filtrates were pooled, and the solvent was removed using a rotary evaporator (Buchi Labortechnik AG, Flawil, Switzerland). The extraction yield was calculated.

The trans-anethole content was analyzed using HPLC. The extract was diluted in methanol into a concentration 
Table 1 Circumscribed central composite experimental design and results of responses, i.e., extraction yield, trans-anethole content in the extract, and trans-anethole content in the plant raw material

\begin{tabular}{|c|c|c|c|c|c|c|c|}
\hline \multirow[t]{2}{*}{ Condition } & \multicolumn{2}{|c|}{ Temperature } & \multicolumn{2}{|l|}{ Time } & \multirow{2}{*}{$\begin{array}{l}\text { Extraction } \\
\text { yield (\%) }\end{array}$} & \multirow{2}{*}{$\begin{array}{l}\text { Trans-anethole con- } \\
\text { tent in extract (\%) }\end{array}$} & \multirow{2}{*}{$\begin{array}{l}\text { Trans-anethole content } \\
\text { in plant raw material (\%) }\end{array}$} \\
\hline & Coded & Actual $\left({ }^{\circ} \mathrm{C}\right)$ & Coded & Actual (min) & & & \\
\hline 1 & -1 & 45.9 & -1 & 12.9 & 10.9 & $13.147 \pm 0.028$ & $1.380 \pm 0.003$ \\
\hline 2 & 1 & 74.1 & -1 & 12.9 & 10.2 & $13.423 \pm 0.013$ & $1.557 \pm 0.001$ \\
\hline 3 & -1 & 45.9 & 1 & 27.1 & 11.5 & $10.724 \pm 0.010$ & $1.029 \pm 0.001$ \\
\hline 4 & 1 & 74.1 & 1 & 27.1 & 12.4 & $8.355 \pm 0.014$ & $1.053 \pm 0.000$ \\
\hline 5 & $-\sqrt{ } 2$ & 40.0 & 0 & 20.0 & 12.8 & $8.447 \pm 0.003$ & $0.845 \pm 0.000$ \\
\hline 6 & $\sqrt{2}$ & 80.0 & 0 & 20.0 & 12.9 & $7.092 \pm 0.008$ & $1.035 \pm 0.001$ \\
\hline 7 & 0 & 60.0 & $-\sqrt{ } 2$ & 10.0 & 10.4 & $14.834 \pm 0.057$ & $1.394 \pm 0.005$ \\
\hline 8 & 0 & 60.0 & $\sqrt{2}$ & 30.0 & 13.4 & $11.240 \pm 0.009$ & $1.405 \pm 0.001$ \\
\hline 9 & 0 & 60.0 & 0 & 20.0 & 11.4 & $15.344 \pm 0.013$ & $1.872 \pm 0.002$ \\
\hline 10 & 0 & 60.0 & 0 & 20.0 & 10.2 & $13.737 \pm 0.016$ & $1.319 \pm 0.002$ \\
\hline 11 & 0 & 60.0 & 0 & 20.0 & 13.4 & $12.097 \pm 0.020$ & $1.464 \pm 0.002$ \\
\hline 12 & 0 & 60.0 & 0 & 20.0 & 10.4 & $9.069 \pm 0.014$ & $1.115 \pm 0.002$ \\
\hline
\end{tabular}

of $0.5 \mathrm{mg} / \mathrm{mL}$ then filtered and injected into the HPLC instrument. Results of the trans-anethole content in the extract and plant raw material were reported. The three responses were optimized using the Design-Expert ${ }^{\circ}$ version 11.0 software program (Stat-Ease, Inc., Minneapolis, MN, USA). Contour plots and response surfaces of the model conditions of the above three responses were constructed, and the prediction equations were reported. The criterion for optimization was to "maximize" the transanethole content in the extract and plant raw material. The condition with the highest desirability value was selected as the optimal condition. The optimal condition provided by the Design-Expert ${ }^{\circ}$ software was used to reextract the C. anisata leaves to confirm the accuracy of the prediction.

\subsubsection{HPLC analysis of trans-anethole}

The analysis of trans-anethole content was done using the Agilent 1260 Infinity system (Agilent Technologies, Santa Clara, CA, USA). Isocratic elution was performed using $\mathrm{ACE}^{\circ}$ Generix $^{\mathrm{TM}}(150 \times 4.6 \mathrm{~mm}$, i.d., $5 \mu \mathrm{m})$ (Advanced Chromatography Technologies Ltd., Aberdeen, Scotland). The column temperature was controlled at $25^{\circ} \mathrm{C}$. Water and methanol in a ratio of 25:75 v/v were used as a mobile phase. The injection volume was $10 \mu \mathrm{L}$, while the detection wavelength was $260 \mathrm{~nm}$.

\subsection{HPLC method validation}

\subsubsection{Linearity and range}

A stock solution of standard trans-anethole in the concentration of $1 \mathrm{mg} / \mathrm{mL}$ was prepared using methanol as a solvent. Then, it was diluted with the same solvent to the following seven concentration levels: $1,5,10,25,50$, 75 , and $100 \mu \mathrm{g} / \mathrm{mL}$. Each solution was filtered and then analyzed by HPLC, and each underwent measurements performed in triplicate. The calibration curve of standard trans-anethole was produced, and a coefficient of determination $\left(R^{2}\right)$ was reported.

\subsection{Limit of detection (LOD) and limit of quantitation (LOQ)}

The 10 injections of a blank solution of methanol were analyzed by HPLC. The standard deviation (SD) was calculated. LOD and LOQ are calculated as per the equations shown in Eqs. 1 and 2:

$\operatorname{LOD}=\frac{3.3 \times \sigma}{S}$

$\operatorname{LOD}=\frac{10 \times \sigma}{S}$

where $\sigma$ is the SD of the response of the blank solution and $S$ is the slope of the calibration curve.

\subsection{Specificity}

The specificity of the analysis was evaluated based on the ultraviolet (UV) spectrum of the peak of the compound as compared with the UV spectrum of the peak of the reference standard. UV spectrums of the three peak regions (top, upslope, and downslope) of the peak of trans-anethole in the $C$. anisata leaf extract were compared with the UV spectrum of the peak of standard trans-anethole. The method was specific when UV 
spectrums of the peak of trans-anethole in C. anisata leaf extract were similar to the UV spectrum of the peak of standard trans-anethole.

\subsection{Precision}

The precision analysis was performed for intraday precision and interday precision. Three concentration levels of standard trans-anethole $(25,50$, and $75 \mu \mathrm{g} / \mathrm{mL})$ were analyzed. The three injection datasets of each concentration level (intraday) and the nine injection datasets (interday, three each day for 3 days) of each concentration level were used to calculate the percent relative SD (\%RSD). The data obtained from the analysis on the same day and among the three different days indicated the intraday precision and interday precision, respectively.

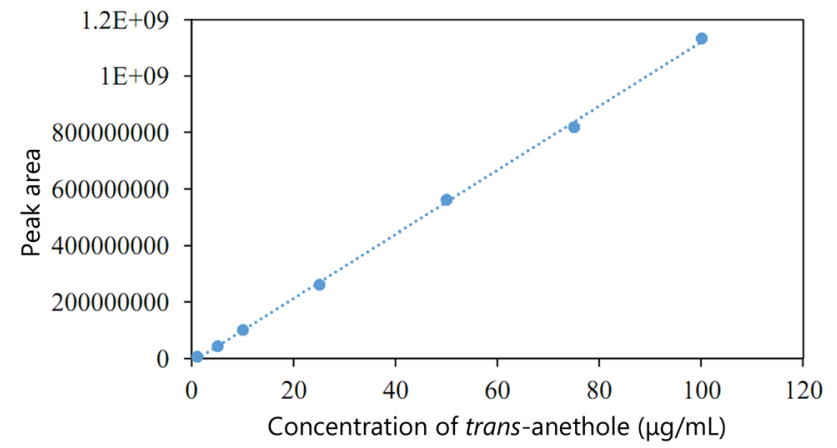

Fig. 1 Calibration curve of standard trans-anethole in the concentration range of $1-100 \mu \mathrm{g} / \mathrm{mL}$. The linear equation was $y=11,335,815 x-11,187,004$ with the $R^{2}$ value of 0.9994

\subsection{Accuracy}

The individual three concentration levels of standard trans-anethole $(25,50$, and $75 \mu \mathrm{g} / \mathrm{mL})$ were added to the C. anisata extract solution with a known amount of transanethole. Each concentration level was analyzed in triplicate. The percent recovery of each concentration level was reported.

\section{Results}

The reliability of chemical analysis results was assured by reliable HPLC method. So, the HPLC method validation was performed in this work. A calibration curve of standard trans-anethole is shown in Fig. 1. The linear equation was $y=11,335,815 x-11,187,004\left(R^{2}=0.9994\right)$ in the concentration range of $1-100 \mu \mathrm{g} / \mathrm{mL}$. LOD and LOQ were $8.4 \mathrm{ng} /$ $\mathrm{mL}$ and $25.4 \mathrm{ng} / \mathrm{mL}$, respectively. Figure 2 presents the HPLC chromatograms of standard trans-anethole and $C$. anisata extract. The simple isocratic system could analyze the trans-anethole content, which was eluted at the retention time of $6.8 \mathrm{~min}$. According to the specificity, this method was specific due to the similarity between the UV spectrums of the three peak regions (i.e., top, upslope, and downslope) of the peak of trans-anethole in C. anisata leaf extract and the UV spectrum of the peak of standard transanethole (Fig. 3). The two maximum absorbance values of trans-anethole were observed at $204 \mathrm{~nm}$ and $258 \mathrm{~nm}$. The precision and accuracy results are shown in Table 2 . The intraday precision was lower than $0.1 \%$, while the interday precision was lower than $1 \%$, and percent recovery was in the range of $96.94-101.25 \%$. As such, these results
Fig. 2 HPLC chromatograms of a trans-anethole $(75 \mu \mathrm{g} / \mathrm{mL})$ and $\mathbf{b}$ extract obtained from Condition $10(500 \mu \mathrm{g} / \mathrm{mL})$. The trans-anethole was eluted at the retention time of $6.8 \mathrm{~min}$
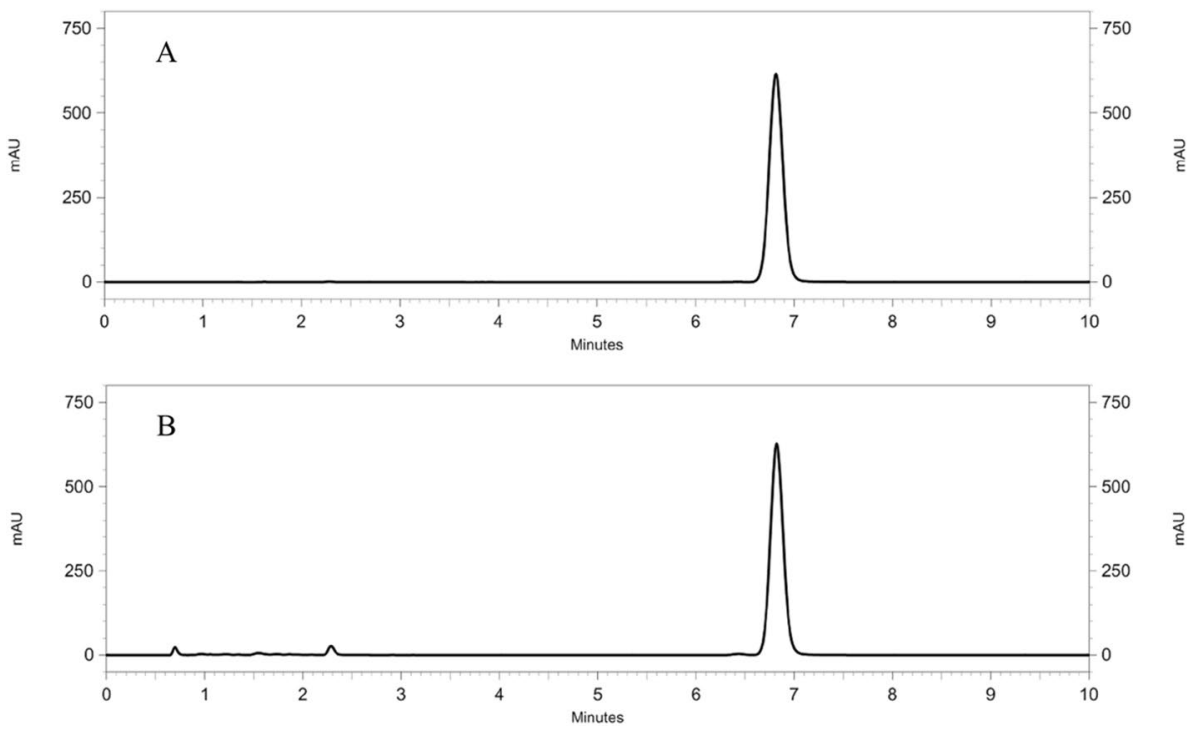

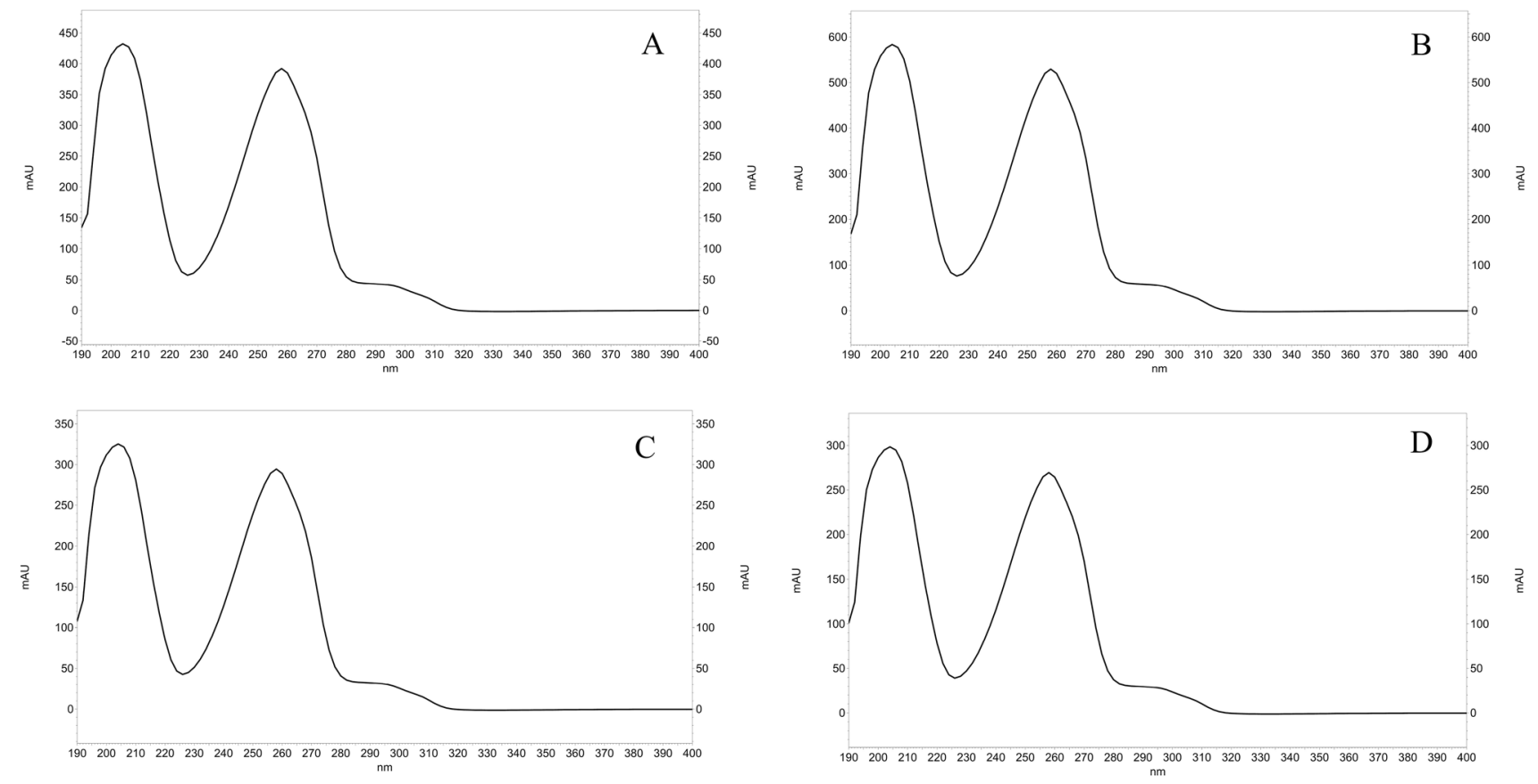

Fig. 3 UV spectrums of a standard trans-anethole (top of the peak) and trans-anethole in the extract at $\mathbf{b}$ top, $\mathbf{c}$ upslope, and $\mathbf{d}$ downslope. The similarity between the UV spectrums of the three

peak regions of the peak of trans-anethole in C. anisata leaf extract and the UV spectrum of the peak of standard trans-anethole was observed

Table 2 Precision and accuracy results

\begin{tabular}{|c|c|c|c|c|c|c|}
\hline \multirow{3}{*}{$\begin{array}{l}\text { Concentration } \\
(\mu \mathrm{g} / \mathrm{mL})\end{array}$} & \multicolumn{4}{|c|}{ Precision (\% RSD) } & \multirow{3}{*}{$\begin{array}{l}\text { Spike concentra- } \\
\text { tion }(\mu \mathrm{g} / \mathrm{mL})\end{array}$} & \multirow{3}{*}{$\begin{array}{l}\text { Accuracy } \\
\text { Recovery (\%) }\end{array}$} \\
\hline & \multicolumn{3}{|c|}{ Intraday } & \multirow[t]{2}{*}{ Interday } & & \\
\hline & Day 1 & Day 2 & Day 3 & & & \\
\hline 25 & 0.05 & 0.10 & 0.04 & 0.20 & 25 & $96.94 \pm 0.05$ \\
\hline 50 & 0.03 & 0.01 & 0.04 & 0.51 & 50 & $101.25 \pm 0.03$ \\
\hline 75 & 0.07 & 0.04 & 0.02 & 0.15 & 75 & $97.75 \pm 0.07$ \\
\hline
\end{tabular}

indicated that the HPLC method was both precise and accurate.

The extraction yields of the 12 conditions ranged from 10.2 to $13.4 \%$. Trans-anethole content in the extract ranged from 7.1 to $15.3 \%$, while trans-anethole content in the plant raw material ranged from 0.8 to $1.9 \%$ (Table 1 ).

Figure 4 displays the contour plots and response surfaces of the model conditions of extraction yield, transanethole content in the extract, and trans-anethole

$Y_{2}=12.5631-0.5004 X_{1}-1.5719 X_{2}-0.6610 X_{1} X_{2}-2.1362 X_{1}^{2}+0.4865 X_{2}^{2}$

$Y_{3}=1.4426+0.0586 X_{1}-0.1051 X_{2}-0.0383 X_{1} X_{2}-0.2291 X_{1}^{2}-0.0005 X_{2}^{2}$ content in the plant raw material. Furthermore, coded and actual equations of each response are shown as follows. The model conditions of extraction yield, trans-anethole content in the extract, and trans-anethole content in the plant raw material were fitted to the linear, quadratic, and quadratic mathematics models, respectively. The coded and actual equations are shown in Eqs. 3-8.

Coded equations:

$$
Y_{1}=11.6583+0.0426 X_{1}+0.8803 X_{2}
$$


A

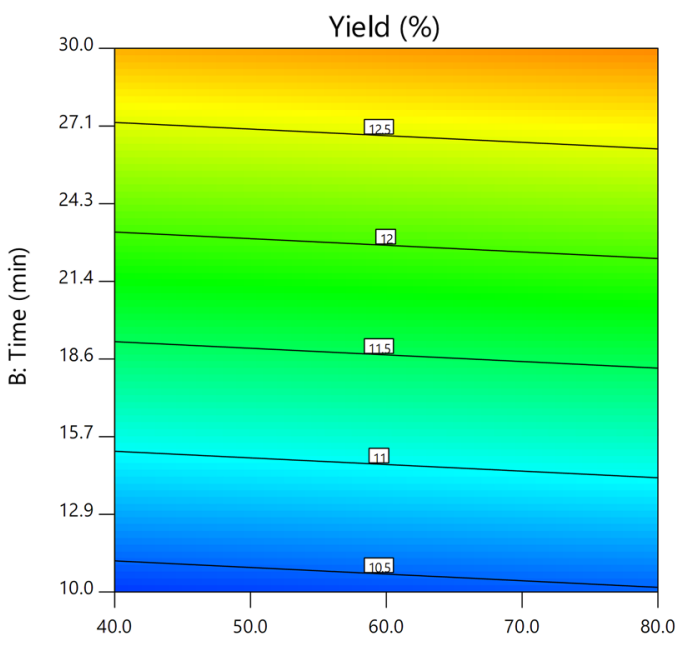

A: Temperature $\left({ }^{\circ} \mathrm{C}\right)$

B

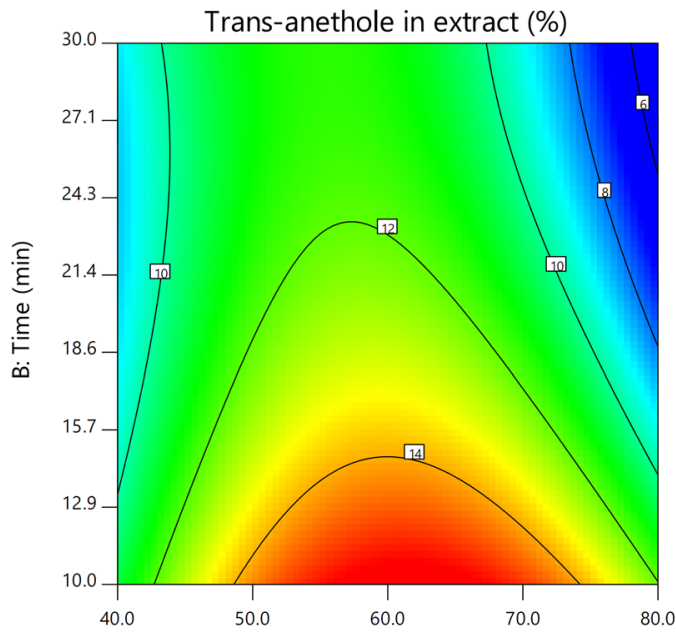

A: Temperature $\left({ }^{\circ} \mathrm{C}\right)$

$\mathrm{C}$

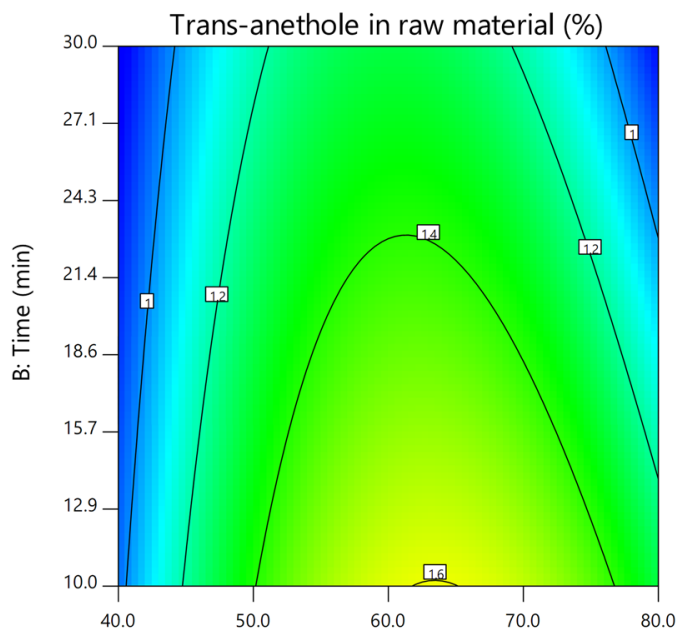

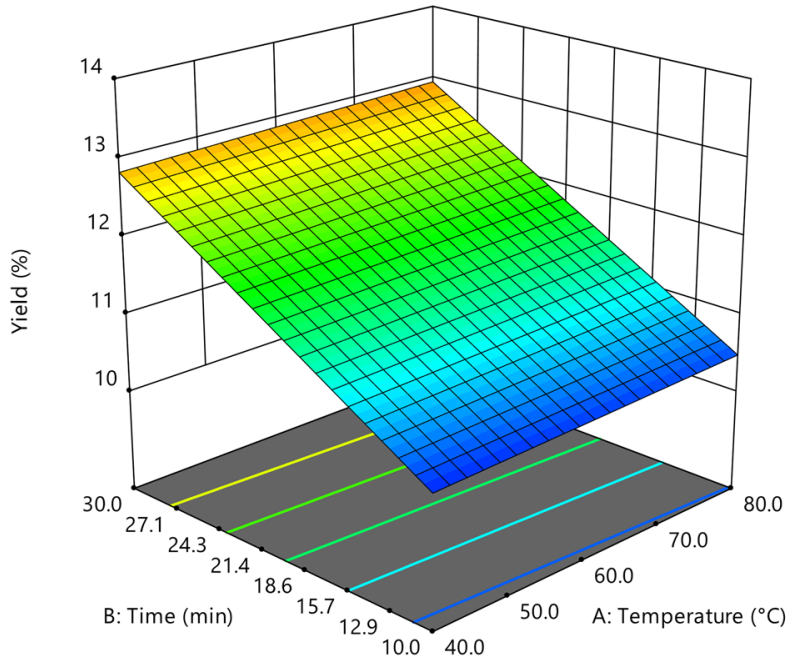
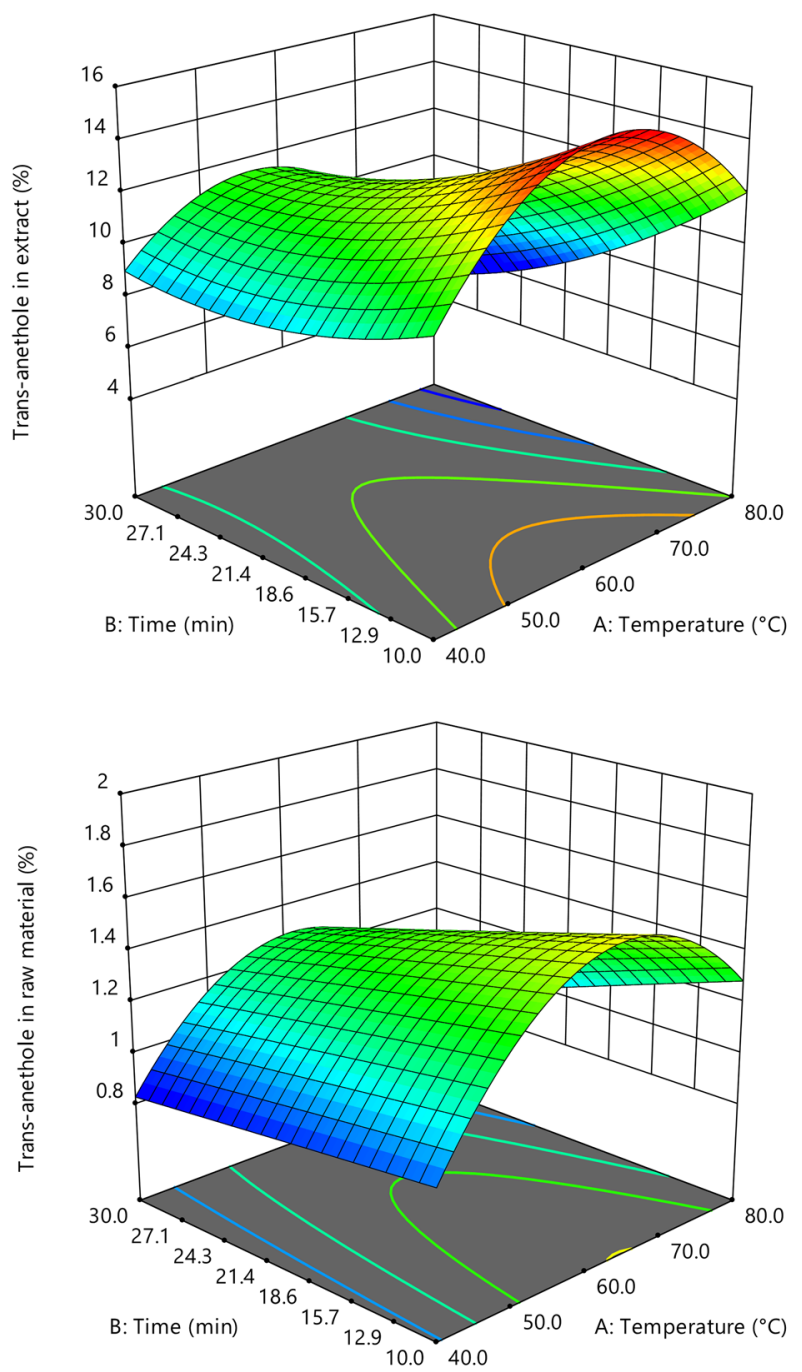

A: Temperature $\left({ }^{\circ} \mathrm{C}\right)$

Fig. 4 Contour plots (left) and response surfaces (right) of model conditions of a extraction yield, $\mathbf{b}$ trans-anethole content in the extract, and $\mathbf{c}$ trans-anethole content in the plant raw material

\section{SN Applied Sciences}


Actual equations:

Extraction yield $(\%)=8.9972+0.0030($ temperature $)+0.1240($ time $)$

Trans - anethole content in extract $(\%)=-23.6253+1.3860$ (temperature) -0.2112 (time)

$$
-0.0066(\text { temperature })(\text { time })-0.0107 \text { (temperature })^{2}+0.0097(\text { time })^{2}
$$

Trans - anethole content in the plant raw material $(\%)=-3.1224+0.1501$ (temperature)

$$
+0.0086(\text { time })-0.0004(\text { temperature })(\text { time })-0.0012(\text { temperature })^{2}-0.00001(\text { time })^{2}
$$

According to the contour plot, the response surface (Fig. 4a), and the above equations, extraction time has a positive effect on the extraction yield, while the extraction temperature had a small impact. Figure $4 b$ and $c$ reveals that a high trans-anethole content in the extract and in plant raw material was achieved when a medium extraction temperature with a short extraction time was used. Figure 5 shows the bar graph of desirability value. The optimal condition that ensured the simultaneous high of trans-anethole content in extract and plant raw material was an extraction temperature of $61.8^{\circ} \mathrm{C}$ and an extraction time of $12.9 \mathrm{~min}$, with a desirability value of 0.794 . The accuracy evaluation by comparison between the predicted value and experimental value found that the prediction by Design-Expert provided a low percent error. Overall, the percent errors of all responses were lower than 20\% (Table 3).
Fig. 5 Desirability chart, when the temperature and time were set as "in range," extraction yield was set as "none," and trans-anethole content in extract and plant raw material were set as "maximize"

Table 3 Predicted values, actual values, and percent error of the prediction

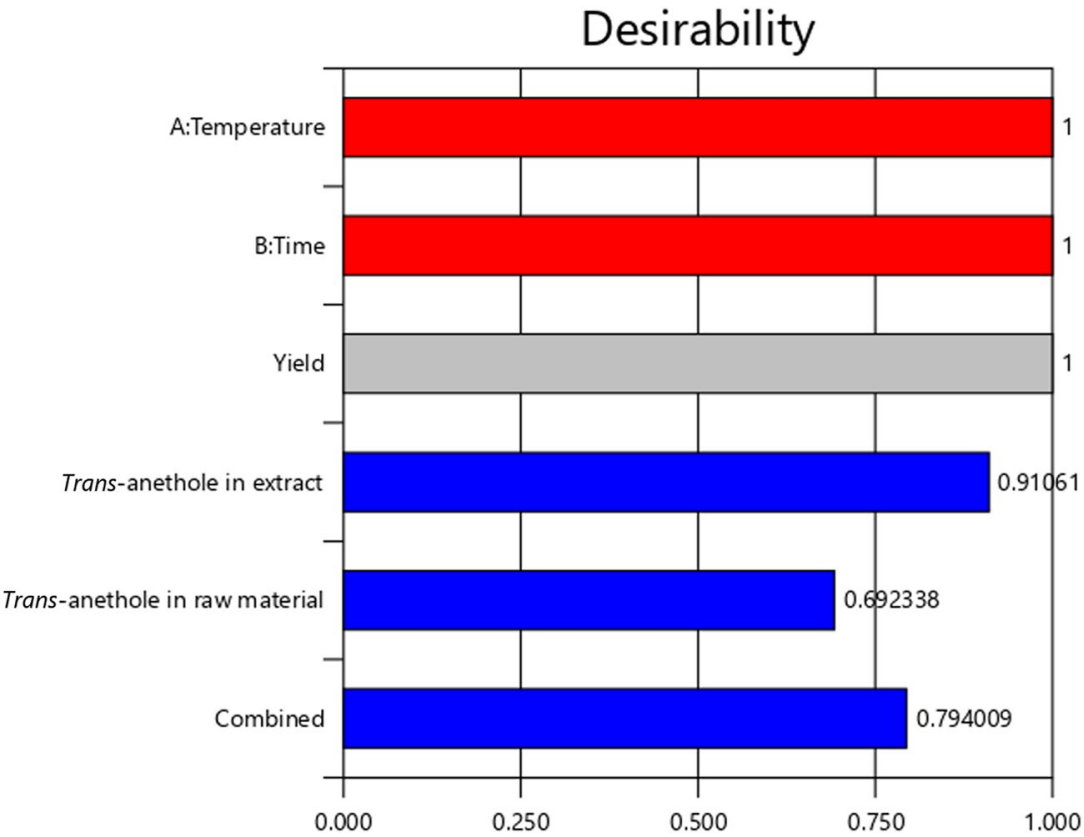

\begin{tabular}{lllc}
\hline Responses & Predicted value & Actual value & Error (\%)* \\
\hline Extraction yield (\%) & 10.8 & 12.5 & 13.6 \\
Trans-anethole content in extract (\%) & 14.61 & $11.87 \pm 0.01$ & -18.79 \\
Trans-anethole in plant raw material (\%) & 1.56 & $1.48 \pm 0.00$ & -5.41 \\
\hline
\end{tabular}

${ }^{*}$ Error $(\%)=($ actual value - predicted value $) \times 100 /$ actual value 


\section{Discussion}

To the best of our knowledge, this is the first work that optimized the extraction parameter of dynamic maceration of trans-anethole from C. anisata leaves. Furthermore, application of modern experimental design provided less time and financial consuming, less chemical use, interaction effect can be identified, and surface response can be characterized [25]. Trans-anethole is volatile by nature and could be degraded by a high extraction temperature with a long extraction time. Extraction temperature and extraction time commonly have a positive impact on the extraction efficiency of thermostable plant compounds. For example, increasing the extraction temperature from 40 to $90^{\circ} \mathrm{C}$ and the extraction time from 1 to $4 \mathrm{~h}$ increased the extraction yield of polysaccharides of Gynura bicolor leaves [26], while increasing the extraction temperature from 30 to $80^{\circ} \mathrm{C}$ and the extraction time from 20 to $180 \mathrm{~min}$ increased the tea protein extraction rate of tea residues [27]. Moreover, Yuan et al. [28] revealed a similar result for the optimization of polysaccharides from wild Russula griseocarnosa, where increasing the extraction temperature from 50 to $90^{\circ} \mathrm{C}$ and extraction time from 1 to $5 \mathrm{~h}$ increased extraction yield of said polysaccharides. According to the crude protein from grapeseed, extraction temperature had a positive impact on protein yield, while extraction time did not affect the protein yield [29]. However, results for optimal extraction temperature and extraction time were found in the other plant species and compounds.

Elsewhere, the extraction temperature increased the extraction rate of soluble soybean polysaccharides, but extraction time had an optimal value range: increasing the extraction time from 2 to $4 \mathrm{~h}$ increased the polysaccharides, while any additional increase in extraction time from 4 to $6 \mathrm{~h}$ decreased the polysaccharides [30]. Hou et al. [31] optimized the extraction condition of phenolic and flavonoid compounds from Melaleuca bracteata leaves and revealed that increasing the extraction temperature increased total phenolic content. Increasing the extraction time from 1 to 3 days led to an increased total phenolic content while increasing the extraction time from 3 to 5 days led to a decrease in the total phenolic content as well as the total flavonoid content. According to the total flavonoid content, the extraction temperature has a small effect. Ni et al. [32] optimized the decoction condition of baicalin from Scutellaria baicalensis roots. Here, the extraction time was varied from 30 to $150 \mathrm{~min}$. It was found that by increasing the extraction time from 30 to $60 \mathrm{~min}$, baicalin content was increased, while when increasing the extraction time from 60 to $150 \mathrm{~min}$, the baicalin content was decreased. The highest baicalin content was achieved at an extraction time of $60 \mathrm{~min}$. Other works reported that extraction time also showed a positive impact on the flavonoid content of Passiflora quadrangularis leaves obtained using the percolation technique; total flavonoids content was increased when extraction time was increased from 24 to $72 \mathrm{~h}$ [33]. Uddin et al. [34] optimized the extraction of polysaccharides from Pleurotus ostreatus. These authors showed that the extraction temperature and extraction time had optimum values of $70^{\circ} \mathrm{C}$ and $60 \mathrm{~min}$, respectively, as shifting higher or lower from these optimum values decreased the polysaccharide yield. Furthermore, an optimal extraction temperature and extraction time were observed in the extraction of polysaccharides from Eucommia ulmoides leaves [35].

Our previous works demonstrated the extraction of plant active compounds from cannabis [36], Centella asiatica [37], and Vernonia cinerea [38]. All works applied circumscribed central composite experimental design, which has been widely used in response to surface modeling and optimization [39]. The above works established the extraction of nonvolatile compounds, i.e., cannabinoids, centelloids, and nitrate, respectively. However, they were different in detail. Extraction of nitrate from $V$. cinerea used water as a solvent. An explosion or ignition during the extraction process could be negligible. Thus, the high applied temperature or boiling could be used, so the high temperature up to $100^{\circ} \mathrm{C}$ for $10-60$ min was designed [38]. According to C. asiatica and cannabis, the active compounds were soluble in ethanol, so ethanol was selected as a safe extraction solvent. Due to the lower flash point and boiling point of ethanol compared with water, the lower extraction temperature was used: $40-60^{\circ} \mathrm{C}$ for $C$. asiatica [37] and $40-80^{\circ} \mathrm{C}$ for cannabis [36], and the longer extraction time could be applied: $60-120 \mathrm{~min}$ for $C$. asiatica [37] and 30-90 min for cannabis [36]. Our present work also used ethanol to extract trans-anethole, a volatile substance, so the low temperature range, $40-80^{\circ} \mathrm{C}$, and the short duration time, 10-30 min were selected. The inclusion of the factors into the experimental design affected the overall result. The comparable experimental design for extraction of active compounds from different plants could be different, due to the different plant components, physicochemical properties of active compounds, the interaction of chemical compounds in plant matrix, etc. This section could be summarized that the optimization of the extraction process was an important step to maximize plant bioactive compounds as well as their activities, especially the extraction of volatile compounds when heating was applied.

Our previous work demonstrated that extraction method, defatting, and solvent-to-solid ratio affected nitrate content of $C$. anisata leaves. Infusion of a non-defatted sample using a solvent-to-solid ratio of 10:1 provided 
the highest nitrate content of the raw material, while decoction of a defatted sample gave the highest nitrate content. Moreover, increasing the solvent-to-solid ratio and defatting of the decoction sample had a huge effect on the nitrate content [17]. Our other previous works optimized the dynamic maceration of $C$. asiatica. Extraction temperature and extraction time were varied to investigate their effects on the content of four markers, including madecassoside, asiaticoside, madecassic acid, and asiatic acid. Madecassoside and asiaticoside were highly extracted using a long extraction time and high extraction temperature, while madecassic acid and asiatic acid were highly extracted at both a high extraction temperature and long extraction time as well as at a low extraction temperature and short extraction time [37]. Other works by our colleagues investigated the effects of the same independent factors, i.e., extraction temperature and extraction time on some responses such as extraction yield and brazilin content. Extraction temperature showed a positive effect on the extraction yield and brazilin content of Caesalpinia sappan heartwood, while extraction time had a minor effect [40]. This outcome was opposite to our present work, where extraction time had a positive effect on extraction yield, but the extraction temperature had a minor effect. Furthermore, other previous works evaluated the effects of extraction temperature and extraction time on the nitrate content of $V$. cinerea. The result showed that both extraction temperature and extraction time have a positive effect on extraction yield and nitrate content. This result was associated with a thermostable property of nitrate, so increasing the temperature and duration time extracted the high content nitrate from $V$. cinerea [38]. All the above data indicated that responsiveness to extraction temperature and extraction time was dependent on the plant species and plant compounds involved.

\section{Conclusions}

This work sought to optimize the dynamic maceration of $C$. anisata leaves to maximize the trans-anethole content. Trans-anethole content was determined by a linear response, specific, precise, and accurate HPLC method. Extraction time had a positive effect on extraction yield, while extraction temperature had a minor effect. Transanethole content in the extract, as well as in plant raw material, was maximized when a medium extraction temperature with a short extraction time was used. The optimal conditions that maximized trans-anethole content were an extraction temperature of $61.8^{\circ} \mathrm{C}$ and an extraction time of $12.9 \mathrm{~min}$. Furthermore, the prediction by Design-Expert was accurate. The condition of dynamic maceration will be used as a guide for the extraction of trans-anethole from $C$. anisata leaves to use as an ingredient of food, beverage, or herbal products.

Acknowledgements We would like to acknowledge Ajarn Nirun Vipunngeun for providing the plant sample of $C$. anisata leaves used in this work. We also thank Miss Kannika Kittiyarangsit and Miss Kittaporn Santichat for their assistance during the extraction step. This paper was proofread and edited by Cambridge Proofreading LLC with the support of the Research Institute of Rangsit University.

\section{Declarations}

Conflict of interest The authors declare that they have no conflicts of interest. This research did not receive any specific grant from funding agencies in the public, commercial, or not-for-profit sectors.

Open Access This article is licensed under a Creative Commons Attribution 4.0 International License, which permits use, sharing, adaptation, distribution and reproduction in any medium or format, as long as you give appropriate credit to the original author(s) and the source, provide a link to the Creative Commons licence, and indicate if changes were made. The images or other third party material in this article are included in the article's Creative Commons licence, unless indicated otherwise in a credit line to the material. If material is not included in the article's Creative Commons licence and your intended use is not permitted by statutory regulation or exceeds the permitted use, you will need to obtain permission directly from the copyright holder. To view a copy of this licence, visit http://creativecommons. org/licenses/by/4.0/.

\section{References}

1. Okokon JE, Etebong EO, Udobang JA, Essien GE (2012) Antiplasmodial and analgesic activities of Clausena anisata. Asian Pac J Trop Med 5(3):214-219. https://doi.org/10.1016/s1995-7645(12) 60027-3

2. Mogale MA, Mkhombo HM, Lebelo SL, Shai LJ, Chauke MA, Freitas Ad (2012) The effects of Clausena anisata (Wild) Hook leaf extracts on selected diabetic related metabolizing enzymes. $J$ Med Plants Res 6(25):4200-4207

3. Arsia Tarnam Y, Nargis Begum T, Deepa NS (2014) Study of in vitro antioxidant, antidiabetic and antibacterial activity of Clausena anisata (Willd). Hook (Rutaceae) leaf extracts. Int J Res Pharmacol Pharmacother 3(2):112-125

4. Okokon JE, Udoh AE, Andrew UE, Amazu LU (2012) Antiinflammatory and antipyretic activities of Clausena anisata. Mol Clin Pharmacol 3(1):47-54

5. Jeon CM, Shin IS, Shin NR, Hong JM, Kwon OK, Kim JH, Oh SR, Bach TT, Hai DV, Quang BH, Choi SH, Lee J, Myung PK, Ahn KS (2016) Clausena anisata-mediated protection against lipopolysaccharide-induced acute lung injury in mice. Int J Mol Med 37(4):1091-1098. https://doi.org/10.3892/ijmm.2016.2515

6. Makirita WE, Chauka LJ, Chacha M (2016) Antimicrobial and cytotoxicity activity of Clausena anisata, Acokanthera shemperii and Olea europaea growing in Tanzania. Eur J Med Plants 14(2):1-9

7. Agyepong N, Agyare C, Adarkwa-Yiadom M, Gbedema SY (2014) Phytochemical investigation and anti-microbial activity of Clausena anisata (Willd), Hook. Afr J Tradit Complement Altern Med 11(3):200-209 
8. Lawal IO, Galadima M, Ogunbamowo PO (2018) Isolation of bioactive compounds of Clausena anisata (Willd.) Hook. growing in South Africa by liquid chromatography-mass spectroscopy profiling, and their antibacterial activities. J Med Plants Econ Dev 2(1):a22

9. Senthilkumar A, Venkatesalu V (2009) Phytochemical analysis and antibacterial activity of the essential oil of Clausena anisata (Willd.) Hook. f. ex. Benth. Int J Integr Biol 5(2):116-120

10. Lawal IO, Grierson DS, Afolayan AJ (2015) Phytochemical and antioxidant investigations of a Clausena anisata hook, a South African medicinal plant. Afr J Tradit Complement Altern Med 12(1):28-37

11. Agyepong N, Agyare C, Ossei PPS, Boakye YD (2015) Antioxidant and in vivo wound healing activities of Clausena anisata. Eur J Med Plants 10(2):1-8

12. Mukandiwa L, Ahmed A, Eloff JN, Naidoo V (2013) Isolation of seselin from Clausena anisata (Rutaceae) leaves and its effects on the feeding and development of Lucilia cuprina larvae may explain its use in ethnoveterinary medicine. J Ethnopharmacol 150(3):886-891. https://doi.org/10.1016/j.jep.2013.09.037

13. Mukandiwa L, Eloff JN, Sibanda DR, Naidoo V (2016) An acetone extract of Clausena anisata may be a potential control agent for flies encountered in cutaneous myiasis. Onderstepoort J Vet Res 83(1):a1045. https://doi.org/10.4102/ojvr.v83i1.1045

14. Pavela R, Maggi F, Lupidi G, Mbuntcha H, Woguem V, Womeni HM, Barboni L, Tapondjou LA, Benelli G (2018) Clausena anisata and Dysphania ambrosioides essential oils: from ethnomedicine to modern uses as effective insecticides. Environ Sci Pollut Res 25(11):10493-10503. https://doi.org/10.1007/ s11356-017-0267-9

15. Aurelie FDG, Pierre BNM, Ascension NM, Lebel TJ (2018) Chemical composition and biocide properties of Clausena anisata (Rutaceae) essential oil against developmental stages of the malaria vector Anopheles coluzzii. Am J Essent Oils Nat Prod 6(1):9-15

16. Govindarajan M (2010) Chemical composition and larvicidal activity of leaf essential oil from Clausena anisata (Willd.) Hook. f. ex. Benth (Rutaceae) against three mosquito species. Asian Pac J Trop Med 3(11):874-877. https://doi.org/10.1016/S19957645(10)60210-6

17. Monton C, Suksaeree J, Luprasong C (2020) Validated reversedphase ion-interaction high-performance liquid chromatography for quantitation of nitrate content of Clausena anisata (Willd.) Hook. f. ex. Benth. leaves. Scientifica. https://doi.org/10.1155/ 2020/6424682

18. Usman LA, Hamid AA, Olawore NO, Fakunle CO, Oladosu IA, Zubair MF (2010) Chemical composition of leaf essential oil of Clausena anisata growing in North-central Nigeria. J Appl Sci Res 6(6):891-894

19. Ekundayo O, Oguntimein BO, Hammerschmidt FJ (1986) Constituents of the essential oil of Clausena anisata leaves. Planta Med 52(6):505-506. https://doi.org/10.1055/s-2007-969274

20. Addae-Mensah I, Asomaning WA, Oteng-Yeboah A, Garneau F-X, Gagnon H, Jean F-I, Moudachirou M, Koumaglo KH (1996) (E)anethole as a major essential oil constituent of Clausena anisata. J Essent Oil Res 8(5):513-516. https://doi.org/10.1080/10412905. 1996.9700678

21. Marinov V, Valcheva-Kuzmanova S (2015) Review on the pharmacological activities of anethole. Scripta Scientifica Pharmaceutica 2(2):14-19

22. Sasidharan S, Chen Y, Saravanan D, Sundram KM, Yoga Latha $L$ (2010) Extraction, isolation and characterization of bioactive compounds from plants' extracts. Afr J Tradit Complement Altern Med 8(1):1-10
23. Eldin $A B$ (2011) General introduction to Design of Experiments (DOE). In: Akyar I (ed) Wide spectra of quality control, vol 2. IntechOpen, London, pp 21-26

24. Durakovic B (2017) Design of experiments application, concepts, examples: State of the art. Period Eng Nat Sci 5(3):421-439

25. Gibson M (ed) (2016) Pharmaceutical preformulation and formulation: A practical guide from candidate drug selection to commercial dosage form, vol 199. Informa Healthcare, New York

26. Yan F, Yang X, Liu C, Huang S, Liao L, Fu C (2014) Extraction optimization of antioxidant polysaccharides from leaves of Gynura bicolor (Roxb. \& Willd.) DC. Food Sci Technol 34:402-407

27. Cui Q, Ni X, Zeng L, Tu Z, Li J, Sun K, Chen X, Li X (2017) Optimization of protein extraction and decoloration conditions for tea residues. Hortic Plant J 3(4):172-176. https://doi.org/10.1016/j. hpj.2017.06.003

28. Yuan Y, Liu Y, Liu M, Chen Q, Jiao Y, Liu Y, Meng Z (2017) Optimization extraction and bioactivities of polysaccharide from wild Russula griseocarnosa. Saudi Pharm J 25(4):523-530. https://doi. org/10.1016/j.jsps.2017.04.018

29. Lv C, Jia X, Li M, Yang J, Zhao G (2011) Optimization of extraction process of crude protein from grape seeds by RSM. Food Sci Technol Res 17(5):437-445. https://doi.org/10.3136/fstr.17.437

30. Li HR, Yuan LB, Xv MS, Zhang WB (2012) Optimization on extraction technique of soluble soybean polysaccharide. Appl Mech Mater 138-139:1156-1161

31. Hou W, Zhang W, Chen G, Luo Y (2016) Optimization of extraction conditions for maximal phenolic, flavonoid and antioxidant activity from Melaleuca bracteata leaves using the response surface methodology. PLoS ONE 11(9):e0162139. https://doi.org/ 10.1371/journal.pone.0162139

32. Ni H, Wu Z, Muhammad I, Lu Z, Li J (2018) Optimization of baicalin water extraction process from Scutellaria baicalensis (a traditional Chinese medicine) by using orthogonal test and HPLC. Rev Bras Farmacogn 28(2):151-155. https://doi.org/10.1016/j. bjp.2018.02.001

33. Echeverry SM, Medina HI, Costa GM, Aragón DM (2018) Optimization of flavonoid extraction from Passiflora quadrangularis leaves with sedative activity and evaluation of its stability under stress conditions. Rev Bras Farmacogn 28(5):610-617. https:// doi.org/10.1016/j.bjp.2018.06.005

34. Uddin Pk MM, Islam MS, Pervin R, Dutta S, Talukder RI, Rahman M (2019) Optimization of extraction of antioxidant polysaccharide from Pleurotus ostreatus (Jacq.) P. Kumm and its cytotoxic activity against murine lymphoid cancer cell line. Plos One 14(1):e0209371. https://doi.org/10.1371/journal.pone.0209371

35. Xu J, Hou H, Hu J, Liu B (2018) Optimized microwave extraction, characterization and antioxidant capacity of biological polysaccharides from Eucommia ulmoides Oliver leaf. Sci Rep 8(1):6561. https://doi.org/10.1038/s41598-018-24957-0

36. Monton C, Madaka F, Settharaksa S, Wunnakup T, Suksaeree J, Songsak T (2019) Optimal condition of cannabis maceration to obtain the high cannabidiol and $\Delta^{9}$-tetrahydrocannabinol content. An Acad Bras Ciênc 91(3):e20190676. https://doi.org/10. 1590/0001-3765201920190676

37. Monton C, Settharaksa S, Luprasong C, Songsak T (2019) An optimization approach of dynamic maceration of Centella asiatica to obtain the highest content of four centelloids by response surface methodology. Rev Bras Farmacogn 29(2):254-261. https:// doi.org/10.1016/j.bjp.2019.01.001

38. Monton C, Luprasong C (2019) Effect of temperature and duration time of maceration on nitrate content of Vernonia cinerea (L.) Less: circumscribed central composite design and method validation. Int J Food Sci. https://doi.org/10.1155/2019/1281635

39. Bhattacharya $S$ (2021) Central composite design for response surface methodology and its application in pharmacy. In: 
Response surface methodology in engineering science. IntechOpen, London, pp 1-19

40. Settharaksa S, Monton C, Charoenchai L (2019) Optimization of Caesalpinia sappan L. heartwood extraction procedure to obtain the highest content of brazilin and greatest antibacterial activity. J Integr Med 17:351-358. https://doi.org/10.1016/j. joim.2019.05.00339
Publisher's Note Springer Nature remains neutral with regard to jurisdictional claims in published maps and institutional affiliations. 